\title{
Analisis Penyebab Kegagalan Mesin Wrapping Menggunakan Failure Mode And Effect Analysis di PT. X
}

\author{
Candrianto ${ }^{1}$, Rizaldi Sardani ${ }^{1}$, Rizki Fadhillah Lubis ${ }^{1}$, M. Zakaria ${ }^{1}$ \\ ${ }^{I}$ Politeknik ATI Padang, Jl. Bungo Pasang Tabing Padang 25171, Indonesia
}

\section{ARTICLE INFORMATION}

Received: May 30, 2021

Revised: June 28, 2021

Available online: June 30, 2021

\section{KEYWORDS}

Failure Mode and Effect Analysis, Risk

Priority Number, Wrapping Machine

\section{CORRESPONDENCE}

Name: Candrianto

E-mail: candriantokemenperin@gmail.com

\begin{abstract}
A B S S T R A A C T
PT. X is an industry that produces green tea and black tea. In this study, there are often problems with the wrapping machine due to the age of use and the tight schedule of usage in the wrapping machine. If the machine operates in an unstable condition, it will greatly affect the results of the production. Damaged components such as cutting blades, heating heaters, thermo control and bearings. By using the Failure Mode and Effect Analysis (FMEA) method and also calculating the Risk Priority Number (RPN) value, the highest RPN value to the lowest is obtained, namely Cutting Knife ( $R P N=100)$, Heater (RPN $=90)$, Thermo Control (RPN $=72$ ) and Bearings ( $R P N=36)$. It can be seen that the cause of damage to the wrapping machine and also the highest RPN calculation is found in the damage to the cutting knife whose RPN value is 100. From the analysis of the damage to the cutting knife, the author provides a suggested repair plan for the company so that it can be implemented in the company which can later improve the quality of the machine to be operated. for the future which cannot be separated from the supervisory role of the operators in charge of their cooperation to improve quality and the quality control team that always monitors quality.
\end{abstract}

\section{PENDAHULUAN}

PT. X merupakan industri hilir teh manufaktur yang mengolah teh bubuk menjadi produk teh celup dan teh seduh yang siap dipasarkan. Dalam memproduksi teh menggunakan berbagai macam dus dalam produks sesuai dengan teh yang dipesan konsumen seperti dus walini BP1, dus walini hitam, dus walini jasmine, dus walini tah hijau, dus walini rasa leci, dus walini rasa mint, dus walini rasa lemon, dus walini amplop, dus goalpara, dan dus gunung mas. Suatu perencanaan produksi dapat tidak lancar apabila ada bagian mesin yang rusak atau tidak bisa beroperasi. Oleh karena itu kerena itu perawatan mesin merupakan kegiatan yang diperlukan dalam kegiatan produksi [1]. Pada PT. X belum memiliki sistem pemeliharaan yang tertata dengan baik menyebabkan sering terjadinya kerusakan dan berhentinya produksi hingga kerusakan selesai diperbaiki. Mesin Wrapping merupakan mesin yang digunakan untuk melakukan proses pengemasan dus dengan plastik OPP dimasukkan kedalam karton (pengkartonan). Permasalahan yang terjadi pada PT. X antara lain yaitu pemanas heater, seal, dan pisau pemotong. Jika mesin tersebut mengalami kerusakan maka akan menghambat proses produksi dan menidentifikasi resiko kegagalan produk cacat.

Perawatan mesin dapat dilakukan sebagai upaya menangani permasalahan yang terjadi pada perusahaan tersebut, salah satunya dengan menggunakan metode Failure Mode and Effect Analysis (FMEA). Penelitian sebelumnya terkait metoda tersebut diantaranya Reza, et al [2] untuk mengetahui penyebab kegagalan mesin Mandrel Tension Reel yang terjadi sehingga bisa dilakukan perbaikan dimana hasil menunjukkan terdapat 8 mode kegagalan dari 2 item yang ada pada subsistem mandrel. Kemudian Sari et al, [3] menggunakan metoda tersebut untuk mengidentifikasi dan menganalisa kegagalan pada produk Woven Bag, dimana terdapat empat jenis kecacatan, yakni cacat anyaman, cacat potong dan jahit, cacat cetakan, dan cacat segel. Puspitasari dan Martanto [4] menggunakan FMEA untuk 
mengidentifikasi resiko kegagalan yang terjadi selama proses produksi pada pembuatan sarung tenun, dimana tujuannya adalah menganalisa moda kegagalan yang menyebabkan cacat produk. Hasil penelitian menyimpulkan moda kegagalan potensial pada proses pembuatan sarung tenun terdiri dari 14 jenis kegagalan, dimana kegagalan tersebut didapatkan berdasarkan dari kegagalan fungsi alat/proses jenis mesin yang beroperasi pada proses pembuatan sarung tenun.

Penelitian yang sama juga dikemukakan Hanif et al, [5] menggunakan Failure Mode and Effect Analysis (FMEA) untuk meminimalisasi adanya rework yang menimbulkan biaya, dimana setiap divisi produksi menimbulkan cacat diatas 5\%. Hasil menunjukkan bahwa nilai RPN kecacatan yang akan dianalisis dengan menggunakan metode FTA yaitu kecacatan retak pada permukaan produk, dan kecacatan pemberian warna dasar yang tidak merata.

Metode ini juga digunakan pada perusahaan manufaktur besi dan baja dimana Anthony [6] menjabarkan hasil penelitian penyebab kerusakan Hot Rooler Table untuk mengidentifikasi dan menganalisis tingkat kerusakan dan penyebabnya dengan penerapan metode FMEA. Berdasarkan hasil penelitian, kerusakan mesin Hot Roller Table didapat bahwa frekuensi kerusakan tertinggi yaitu pada rotary coupling dengan down time presentase sebesar 26,9\%. Dari Analisa FMEA, didapat dua komponen yang mempunyai nilai RPN sangat tinggi yang di kategorikan sebagai potential severity yaitu bearing yang pertama dengan nilai RPN sebesar 392 dan yang kedua adalah seal ring dengan nilai RPN sebesar 294. Kedua koponen tersebut menjadi prioritas utama perbaikan pada bagian unit furnace section mill terutama untuk aspek mesin dan manusia. Metoda FMEA ini juga digunakan untuk pencegahan resiko seperti diteliti oleh Andiyanto et al, [7] dan perbaikan kualitas, Hanif et al, [8].

\section{METODOLOGI}

Penelitian ini menggunakan metode pendekatan deskriptif [9] untuk menganalisis perawatan mesin Wrapping menggunakan metode Failure Mode And Effect Analysis (FMEA) [10]. Langkah-langkah yang dilakukan dalam melakukan penelitian ini adalah sebagai berikut:

\section{Metode Pengumpulan Data}

Yang digunakan adalah studi literatur, wawancara dan kuisioner. Studi literatur dilakukan dengan cara mengumpulkan data atau dokumen terkait penelitian melalui referensi, buku-buku dan wawancara serta kuisioner dilakukan dengan memberikan pertanyaanpertanyaan kepada bagian mesin wrapping.

\section{Analisis Data}

Data-data yang akan dianalisis berupa mesin wrapping terdiri dari Pemanas heater, seal, dan pisau pomotong. Prosesnya menggunakan pendekatan FMEA (Failure Mode And Effect Analysis) untuk pengendalian kualitas mesin wrapping pada PT. X. Langkah-langkah FMEA (Failure Mode And Effect Analysis) [7] adalah mengidentifikasi fungsi pada proses produksi, mengidentifikasi potensi failure mode proses produksi, mengidentifikasi potensi efek kegagalan produksi dan engidentifikasi penyebab-penyebab kegagalan proses produksi, mengidentifikasi mode-mode deteksi proses produksi, menentukan rating terhadap severity, occurance, detecion dan RPN proses produksi dan usulan perbaikan.

\section{Menghitung FMEA}

$$
\begin{gathered}
\text { Xgeo }=\sqrt[n]{x_{1}} x_{2} \cdot x_{3} \cdot x_{4},,, x_{5} \\
\mathrm{n}=\text { Jumlah data } \\
\mathrm{X}_{1}=\text { Nilai rating ke } \mathrm{i}
\end{gathered}
$$

Setelah pemberian rating dilakukan, nilai RPN dari setiap penyebab kegagalan dihitung dengan rumus:

$\mathrm{RPN}=$ Severity $x$ Occurance $x$ Detection

\section{HASIL DAN PEMBAHASAN}

PT. X memiliki dua mesin wrapping sumber pemanas untuk proses produksi pengemasan dus teh dengan menggunakan plastik OPP atau disebut mesin wrapping. Mengingat pentingnya mesin wrapping, maka mesin wrapping haruslah selalu dalam keadaan baik dan siap pakai. Namun selama pengamatan yang dilakukan mesin ini sering mengalami kerusakan. Kerusakan yang terjadi yaitu pada pemanas heater dan seal yang berupa plastik sambungan bawah lipatan kiri kanan pada dinding tersebut, dan pisau pemotong pada plastik tidak berfungsi dengan baik. Kerusakan yang terjadi baik itu kerusakan kecil hingga kerusakan total, maka mesin wrapping tidak dapat beroperasi karena hasil pengemasan dus yang dihasilkan hancur dan rusak serta produk tersebut tidak dapat dikemas dan dipasarkan lagi. Jumlah kerusakan (Breakdown) mesin wrapping selama periode Januari 2019 sampai Maret 2019 dapat dilihat pada tabel 1.

Dari Tabel 1 dapat dilihat total kerusakan dua mesin wrapping selama periode Januari 2019 sampai Maret 2019 yaitu sebanyak 12 kali kerusakan yang menyebabkan Breakdown, dimana terjadi kerusakan yang terjadi di mesin 1 sebanyak 7 kali, sedangkan kerusakan yang terjadi dimesin 2 sebanyak 5 kali. Jadi total keseluruhan kerusakan selama 3 bulan tersebut 
sebanyak 12 kali. Jika terjadi kerusakan total pada mesin Wrapping ini, maka perusahaan harus mengeluarkan biaya perbaikan untuk 1 mesin Wrapping yaitu terlihat pada tabel 2 dan jika terjadi kerusakan kecil pada mesin wrapping ini, maka biaya yang akan dikeluarkan terlihat pada tabel 3 .

Tabel 1. Breakdown Mesin Wrapping Tahun 2019

\begin{tabular}{ccccc}
\hline \multirow{2}{*}{ No } & Bulan & \multicolumn{2}{c}{ Jumlah Kerusakan } & Total \\
\cline { 3 - 4 } & & Mesin 1 & Mesin 2 & (Kali) \\
\hline 1 & Januari 2019 & 4 & 3 & 7 \\
2 & Februari 2019 & 3 & 2 & 5 \\
3 & Maret 2019 & 0 & 0 & 0 \\
\hline Total & & 7 & 5 & 12 \\
\hline
\end{tabular}

Sumber: PT. X.2019

Tabel 2. Biaya Komponen yang Dibutuhkan untuk Memperbaiki Mesin Wrapping Jika Rusak Total Tahun 2019

\begin{tabular}{lrlr}
\hline Nama Barang & Harga (Rp) & Kebutuhan & Total (Rp) \\
\hline Pisau Pemotong & 5.000 .000 & 2 Buah & 10.000 .000 \\
Heater Pemanas & 250.000 & 2 Buah & 500.000 \\
Thermocontrol & 450.000 & 2 Buah & 900.000 \\
Bearing & 100.000 & 2 Buah & 200.000 \\
Sparepart & 250.000 & 4 Buah & 1.000 .000 \\
\hline Jumlah & & & 12.600 .000 \\
\hline Sumber: PT. X 2019 & & &
\end{tabular}

Dari Tabel 2 dapat dilihat bahwa jika mesin Wrapping mengalami kerusakan total maka biaya yang dikeluarkan oleh perusahaan sebesar Rp. 12.600.000 sementara jika biaya kerusakan kecil maka perusahaan harus mengeluarkan sebesar Rp. 5.750.000. pada kerusakan kecil peralatan yang digunakan lebih sedikit kebutuhannya seperti: pisau pemotong, sparepart, dan heater pemenas dan pada kerusakan peralatan kecil yang sering digunakan jika terjadi kerusakan kecil. Sedangkan kerusakan total peralatan yang digunakan lebih banyak karena sesuai dengan kebutuhan pada saat terjadi kerusakan. yang terlihat pada Tabel 3.

Tabel 3. Biaya Komponen yang Dibutuhkan untuk Memperbaiki Mesin Wrapping Jika Rusak Kecil Tahun $\underline{2019}$

\begin{tabular}{|c|c|c|c|}
\hline Peralatan & Kebutuhan & Harga/Buah & Total \\
\hline $\begin{array}{l}\text { Pisau } \\
\text { Pemotong }\end{array}$ & 1 Buah & Rp 5.000.000 & Rp 5.000.000 \\
\hline Heater & 1 buah & 250.000 & 250.000 \\
\hline Sparepart & 2 Buah & 250.000 & 500.000 \\
\hline Jumlah & & & Rp 5.750.000 \\
\hline
\end{tabular}

Sumber: PT. X 2019
Selama periode Januari sampai Maret 2019 kerusakan total yang telah terjadi untuk kedua mesin diatas adalah sebanyak 1 kali, sehingga:

Biaya untuk kerusakan total:

2 x Rp12.600.000 = Rp25.200.000

Dan sebayak 3 kali kerusakan kecil, sehingga:

Biaya kerusakan kecil:

$3 \times \operatorname{Rp} 5.750 .000=\operatorname{Rp} 17.250 .000$

Untuk menentukan jenis kerusakan mesin wrapping dengan cara menentukan nilai, Severity (keparahan), Occurance (keterjadian), Detection (deteksi penyebab).

\section{Severity (Keparahan)}

Berdasarkan hasil kuisioner menyatakan bahwa Savaerity adalah langkah pertama untuk menganalisa resiko, yaitu menghitung seberapa besar dampak atau intenstas kejadian mempengaruhi hasil akhir proses dan dapat dilihat pada tabel 4 .

Tabel 4. Nilai Severity (Keparahan)

\begin{tabular}{|c|c|c|}
\hline Pengaruh & Severity & Rangking \\
\hline $\begin{array}{l}\text { Berbahaya } \\
\text { tanpa } \\
\text { peringatan }\end{array}$ & $\begin{array}{l}\text { Tingkat keparahan yang } \\
\text { sangat tinggi ketika model } \\
\text { kegagalan potensial } \\
\text { mempengaruhi operasional } \\
\text { sistim yang aman tanpa } \\
\text { peringatan }\end{array}$ & 10 \\
\hline $\begin{array}{l}\text { Berbahaya } \\
\text { dengan } \\
\text { peringatan }\end{array}$ & $\begin{array}{l}\text { Tingkat keparahan yang } \\
\text { sangat tinggi ketika model } \\
\text { kegagalan potensial } \\
\text { mempengaruhi operasi } \\
\text { sistim yang aman dengan } \\
\text { peringatan }\end{array}$ & 9 \\
\hline $\begin{array}{l}\text { Sangat } \\
\text { tinggi }\end{array}$ & $\begin{array}{llr}\text { Sistim operasi } & \text { dengan } \\
\text { gagal merusak } & \text { tanpa } \\
\text { mengorbankan } & \\
\text { keselamatan } & \\
\end{array}$ & 8 \\
\hline Tinggi & $\begin{array}{l}\text { Sistim beroperasi dengan } \\
\text { kerusakan }\end{array}$ & 7 \\
\hline Sedang & $\begin{array}{l}\text { Sistim bisa operasi rusak } \\
\text { ringan }\end{array}$ & 6 \\
\hline Rendah & $\begin{array}{l}\text { Sistim beroperasi tanpa } \\
\text { rusak ringan }\end{array}$ & 5 \\
\hline $\begin{array}{l}\text { Sangat } \\
\text { rendah }\end{array}$ & $\begin{array}{l}\text { Sistim beroperasi dengan } \\
\text { penurunan yang signifikan } \\
\text { dari kinerja }\end{array}$ & 4 \\
\hline Kecil & $\begin{array}{l}\text { Sistim dapat dioperasikan } \\
\text { dengan beberapa } \\
\text { penurunan kinerja }\end{array}$ & 3 \\
\hline Sangat kecil & $\begin{array}{l}\text { Sistim beroperasi dengan } \\
\text { minimal gangguan }\end{array}$ & 2 \\
\hline Tidak & Tidak ada efek & 1 \\
\hline
\end{tabular}


Tabel 5. Hasil Kuisioner Severity

\begin{tabular}{|c|c|c|c|c|c|}
\hline Komponen & $\begin{array}{l}\text { Bentuk } \\
\text { Kegagalan } \\
\end{array}$ & $\begin{array}{l}\text { Mandor } \\
\text { Besar }\end{array}$ & $\begin{array}{l}\text { Opr } \\
\text { Mesin }\end{array}$ & $\begin{array}{l}\text { Opr } \\
\text { Mesin } \\
\end{array}$ & $\begin{array}{l}\text { Quality } \\
\text { Control }\end{array}$ \\
\hline $\begin{array}{l}\text { Pisau } \\
\text { pemotong }\end{array}$ & Tidak tajam & 3 & 6 & 5 & 5 \\
\hline Heater & $\begin{array}{l}\text { Plastik tidak } \\
\text { lengket }\end{array}$ & 7 & 6 & 6 & 6 \\
\hline $\begin{array}{l}\text { Thermo } \\
\text { Control }\end{array}$ & $\begin{array}{l}\text { Pengaturan } \\
\text { suhunya tidak } \\
\text { konstan } \\
\text { menyebabkan } \\
\text { suhu sering } \\
\text { berubah }\end{array}$ & 5 & 6 & 6 & 6 \\
\hline Bearing & $\begin{array}{l}\text { Berputar tidak } \\
\text { seimbang. } \\
\text { Silinder } \\
\text { penggerak } \\
\text { bearing hilang }\end{array}$ & 6 & 6 & 4 & 4 \\
\hline
\end{tabular}

Nilai Saverity (S) didapat dari format kuesinoner saverity dan didalam kuesioner tersebut terdapat pembobotan dari rating 1-10. Hal ini dapat dilihat pada tabel 5.

a) Pisau Pemotong

$$
\begin{aligned}
\text { Saverity }=\sqrt[4]{3.6 .5 .5} \\
=\sqrt[4]{450} \\
=4,6 \rightarrow 5
\end{aligned}
$$

b) Heater Pemanas

$$
\begin{aligned}
\text { Saverity }=\sqrt[4]{7.6 .6 .6} \\
=\sqrt[4]{1512} \\
=6,2 \rightarrow 6
\end{aligned}
$$

c) Thermo Control

$$
\begin{aligned}
\text { Saverity }=\sqrt[4]{5.6 .6 .6} \\
=\sqrt[4]{1080} \\
=5,7 \rightarrow 6
\end{aligned}
$$

d) Bearing

$$
\begin{aligned}
\text { Saverity }=\sqrt[4]{6.6 .4 .4} \\
=\sqrt[4]{385} \\
=4,4 \rightarrow 4
\end{aligned}
$$

\section{Occurance (Keterjadian)}

Apabila ditentukan rating pada proses saverity, maka tahap selanjutnya adalah menentukan rating terhadap nilai occurance. Occurance yang merupakan

\begin{tabular}{|c|c|c|}
\hline $\begin{array}{l}\text { Probabilitas dari } \\
\text { Kegagalan }\end{array}$ & $\begin{array}{l}\text { Kegagagalan } \\
\text { Probabilitas }\end{array}$ & Rangking \\
\hline \multirow{2}{*}{$\begin{array}{l}\text { Sangat tinggi: kegagalan } \\
\text { hampir tidak terhindar }\end{array}$} & $>1$ dalam 2 & 10 \\
\hline & $>1$ dalam 3 & 9 \\
\hline \multirow{2}{*}{$\begin{array}{l}\text { Tinggi: berulang } \\
\text { kegagalan }\end{array}$} & 1 dalam 8 & 8 \\
\hline & 1 dalam 20 & 7 \\
\hline \multirow{3}{*}{$\begin{array}{l}\text { Sedang: kegagalan } \\
\text { sesekali }\end{array}$} & 1 dalam 80 & 6 \\
\hline & 1 dalam 400 & 5 \\
\hline & 1 dalam 2.000 & 4 \\
\hline \multirow{2}{*}{ Rendah: relatif sedikit } & 1 dalam 15.000 & 3 \\
\hline & 1 dalam 150.000 & 2 \\
\hline $\begin{array}{l}\text { Remote: kegagalan tidak } \\
\text { mungkin }\end{array}$ & $<$ dalam 1.500 .000 & 1 \\
\hline
\end{tabular}
kemungkinan bahwa penyebab kerusakan yang terjadi. Skala dalam penilaian rating dalam tabel occurance dimulai dari skala 1-10, dimana rating 10 berada pada tingkat kejadian kegagalan pada proses produksi yang paling tinggi. Hal ini dapat dilihat pada tabel 6 . Selanjutnya Nilai Occurance $(\mathrm{O})$ didapat dari format kuesinoner dan dalam kuesioner tersebut terdapat pembobotan dari rating 1-10. Hal ini dapat dilihat pada tabel 7 .
Tabel 6. Nilai Occuramce

Tabel 7 Hasil Kuisioner Occurance

\begin{tabular}{llcccc}
\hline Komponen & $\begin{array}{l}\text { Bentuk } \\
\text { Kegagalan }\end{array}$ & $\begin{array}{l}\text { Mandor } \\
\text { Besar }\end{array}$ & $\begin{array}{l}\text { Opr } \\
\text { Mesin }\end{array}$ & $\begin{array}{l}\text { Opr } \\
\text { Mesin }\end{array}$ & $\begin{array}{l}\text { Quality } \\
\text { Control }\end{array}$ \\
\hline $\begin{array}{l}\text { Pisau } \\
\text { pemotong }\end{array}$ & Tidak tajam & 1 & 5 & 5 & 5 \\
\hline Heater & $\begin{array}{l}\text { Plastik tidak } \\
\text { lengket }\end{array}$ & 1 & 5 & 4 & 4 \\
\hline & $\begin{array}{l}\text { Pengaturan } \\
\text { suhu tidak } \\
\text { konstan } \\
\text { menyebabkan } \\
\text { suhu sering } \\
\text { bermtrol }\end{array}$ & 1 & 4 & 5 & 5 \\
& $\begin{array}{l}\text { Berputar tidak } \\
\text { seimbang. } \\
\text { Silinder } \\
\text { penggerak } \\
\text { bearing hilang }\end{array}$ & & & & \\
\hline Bearing & & & & & \\
\hline
\end{tabular}

a) Pisau Pemotong

$$
\begin{aligned}
\text { Occurance } & =\sqrt[4]{1.5 .5 .5} \\
& =\sqrt[4]{125} \\
& =3,3 \rightarrow 4
\end{aligned}
$$

b) Heater Pemanas

$$
\begin{aligned}
\text { Occurance }=\sqrt[4]{1.5 .4 .4} \\
\\
=\sqrt[4]{80} \\
=2.9 \rightarrow 3
\end{aligned}
$$

c) Thermo Control

$$
\begin{aligned}
& \text { Occurance }=\sqrt[4]{1.4 .5 .5} \\
&=\sqrt[4]{100} \\
&=3,1 \rightarrow 3
\end{aligned}
$$

d) Bearing

$$
\begin{aligned}
& \text { Occurance }=\sqrt[4]{1.4 .4 .4} \\
&=\sqrt[4]{64} \\
&=2,8 \rightarrow 3
\end{aligned}
$$

\section{Detection (Deteksi Penyebab)}

Detection merupakan suatu upaya untuk mengetahui setiap metode kerusakan yang terjadi pada mesin wrapping. Rank penilaian tabel detection dan di dalam 
kuesioner tersebut pembobotan dari rating 1-10. Hal ini dapat dilihat pada tabel 8. Nilai Detection (D) didapat dari format kuesinoner dan di dalam kuesioner tersebut terdapat pembobotan dari rating 1-10. Hal ini dapat dilihat pada tabel 9 .

\section{Tabel 8 Nilai Detection}

\begin{tabular}{|c|c|c|}
\hline Deteksi & $\begin{array}{l}\text { Kemungkinan Deteksi } \\
\text { dengan Desain Pengendalian }\end{array}$ & Ranking \\
\hline $\begin{array}{l}\text { Ketidak } \\
\text { tentuan yang } \\
\text { absolut atau } \\
\text { mutlak }\end{array}$ & $\begin{array}{l}\text { Desain kontrol tidak dapat } \\
\text { mendeteksi potensi } \\
\text { penyebab/mekanisme dan } \\
\text { modus kegagalan berikutnya }\end{array}$ & 10 \\
\hline $\begin{array}{l}\text { Sangat } \\
\text { terpencil }\end{array}$ & $\begin{array}{l}\text { Kesempatan kontrol desain } \\
\text { akan mendeteksi potensi } \\
\text { penyebab/mekanisme dan } \\
\text { model kegagalan berikutnya }\end{array}$ & 9 \\
\hline $\begin{array}{l}\text { Sangat } \\
\text { rendah }\end{array}$ & $\begin{array}{l}\text { Yang sangat rendah } \\
\text { kesempatan kontrol desain } \\
\text { akan mendeteksi potensi } \\
\text { penyebab/mekanisme dan } \\
\text { model kegagalan berikutnya }\end{array}$ & 7 \\
\hline Rendah & $\begin{array}{l}\text { Rendah kesempatan kontrol } \\
\text { desain akan mendeteksi } \\
\text { potensi penyebab/mekanisme } \\
\text { dan model kegagalan berikut }\end{array}$ & 6 \\
\hline Moderat & $\begin{array}{l}\text { Sedang kesempatan kontrol } \\
\text { desain akan mendeteksi } \\
\text { potensi penyebab/mekanisme } \\
\text { dan model kegagalan } \\
\text { berikutnya }\end{array}$ & 5 \\
\hline Cukup tinggi & $\begin{array}{l}\text { Cukup tinggi kesempatan } \\
\text { kontrol desain akan } \\
\text { mendeteksi potensi } \\
\text { penyebab/mekanisme dan } \\
\text { model kegagalan berikutnya }\end{array}$ & 4 \\
\hline Tinggi & $\begin{array}{l}\text { Tinggi kesempatan kontrol } \\
\text { desain akan mendeteksi } \\
\text { potensi penyebab/mekanisme } \\
\text { dan model kegagalan } \\
\text { berikutnya }\end{array}$ & 3 \\
\hline Sangat tinggi & $\begin{array}{l}\text { Sangat tinggi kesempatan } \\
\text { kontrol desain akan } \\
\text { mendeteksi potensi } \\
\text { penyebab/mekanisme dan } \\
\text { model kegagalan berikutnya }\end{array}$ & 2 \\
\hline $\begin{array}{l}\text { Hampir } \\
\text { tertentu }\end{array}$ & $\begin{array}{l}\text { Kontrol desain akan } \\
\text { mendeteksi potensi } \\
\text { penyebab/mekanisme dan } \\
\text { model kegagalan berikutnya }\end{array}$ & 1 \\
\hline
\end{tabular}

Tabel 9. Hasil Kuisoner Detection

\begin{tabular}{|c|c|c|c|c|c|}
\hline Komponen & $\begin{array}{l}\text { Bentuk } \\
\text { Kegagalan } \\
\end{array}$ & $\begin{array}{l}\text { Mandor } \\
\text { Besar }\end{array}$ & $\begin{array}{l}\text { Opr } \\
\text { Mesin } \\
\end{array}$ & $\begin{array}{l}\text { Opr } \\
\text { Mesin } \\
\end{array}$ & $\begin{array}{l}\text { Quality } \\
\text { Control } \\
\end{array}$ \\
\hline $\begin{array}{l}\text { Pisau } \\
\text { pemotong }\end{array}$ & Tidak tajam & 8 & 3 & 6 & 6 \\
\hline Heater & $\begin{array}{l}\text { Plastik tidak } \\
\text { lengket }\end{array}$ & 9 & 3 & 5 & 5 \\
\hline $\begin{array}{l}\text { Thermo } \\
\text { Control }\end{array}$ & $\begin{array}{l}\text { Pengaturan } \\
\text { suhu tidak } \\
\text { konstan } \\
\text { menyebabkan } \\
\text { suhu sering } \\
\text { berubah }\end{array}$ & 3 & 3 & 5 & 5 \\
\hline Bearing & $\begin{array}{l}\text { Berputar tidak } \\
\text { seimbang. } \\
\text { Silinder } \\
\text { penggerak } \\
\text { bearing hilang }\end{array}$ & 2 & 3 & 6 & 6 \\
\hline
\end{tabular}

a) Pisau Pemotong

$$
\begin{aligned}
& \text { Detection }=\sqrt[4]{8.3 .6 .6} \\
&=\sqrt[4]{432} \\
&=4,5 \rightarrow 5
\end{aligned}
$$

b) Heater Pemanas

$$
\begin{aligned}
& \text { Detection }=\sqrt[4]{9.3 .5 .5} \\
&=\sqrt[4]{675} \\
&=5
\end{aligned}
$$

c) Thermo Control

$$
\begin{aligned}
\text { Detection }=\sqrt[4]{3.3 .5 .5} \\
=\sqrt[4]{225} \\
=3.8 \rightarrow 4
\end{aligned}
$$

d) Bearing

$$
\begin{aligned}
& \text { Detction }=\sqrt[4]{2.3 .6 .6} \\
&=\sqrt[4]{216} \\
&=2,8 \rightarrow 3
\end{aligned}
$$

Nilai Risk Priority Number (RPN)

Nilai dari Risk Priority Number (RPN) dihitung dengan menggunakan rumus :

$\mathrm{RPN}=$ Severity $x$ Occurrance $x$ Detection. Hal ini dapat dilihat pada tabel 10 .

Tabel 10. Nilai Risk Priority Number (RPN)

\begin{tabular}{clcccc}
\hline No & Jenis-Jenis Kerusakan & S & O & D & RPN \\
\hline 1 & Pisau pemotong & 5 & 4 & 5 & 100 \\
2 & Heater & 6 & 3 & 5 & 90 \\
3 & Thermo Control & 6 & 3 & 4 & 72 \\
4 & Bearing & 4 & 3 & 3 & 36 \\
\hline Total & & & & 298 \\
\hline
\end{tabular}

Berdasarkan tabel 10 di atas, jenis-jenis kerusakan yang mempunyai pengaruh tertinggi adalah pisau pemotong dengan nilai RPN 100 karena pisau pemotong mendapatkan pembobotan nilai dari severity, occurance dan detection yang relatif tinggi. Setelah mengetahui penyebab tingginya pisau pemotong yang terjadi pada 
mesin wrapping saat proses pembungkusan dus teh di PT $\mathrm{X}$. Adapun langkah perbaikan mutu pada pisau pemotong sebagai berikut:

Tabel 11. Usulan Tindakan Perbaikan

\begin{tabular}{|c|c|c|c|}
\hline Faktor & Masalah & Penyebab & $\begin{array}{l}\text { Rencana } \\
\text { Perbaikan }\end{array}$ \\
\hline Material & $\begin{array}{l}\text { Bahan pisau } \\
\text { pemotong } \\
\text { kurang } \\
\text { bagus }\end{array}$ & & $\begin{array}{l}\text { 1. Mengganti } \\
\text { pisau } \\
\text { pemotong } \\
\text { yang rusak } \\
\text { dengan yang } \\
\text { lebih bagus } \\
\text { 2. Melakukan } \\
\text { pengecekan } \\
\text { rutin terhadap } \\
\text { mesin } \\
\text { wrapping }\end{array}$ \\
\hline $\begin{array}{l}\text { Kontruksi } \\
\text { Mesin }\end{array}$ & $\begin{array}{l}\text { Mata pisau } \\
\text { sudah } \\
\text { tumpul }\end{array}$ & $\begin{array}{l}\text { Usia } \\
\text { pemakaian } \\
\text { pisau }\end{array}$ & $\begin{array}{l}\text { 1. Mengasah } \\
\text { kembali } \\
\text { mata pisau } \\
\text { yang sudah } \\
\text { tumpul } \\
\text { 2. Melakukan } \\
\text { pemeriksaan } \\
\text { rutin agar } \\
\text { mesin jadi } \\
\text { terawat }\end{array}$ \\
\hline $\begin{array}{l}\text { Metode } \\
\text { Kerja }\end{array}$ & $\begin{array}{l}\text { Hanya satu } \\
\text { mesin yang } \\
\text { dipakai } \\
\text { perusahaan }\end{array}$ & $\begin{array}{l}\text { Tidak } \\
\text { adanya } \\
\text { jadwal } \\
\text { pemakaian } \\
\text { mesin }\end{array}$ & $\begin{array}{l}\text { Mengatur } \\
\text { waktu } \\
\text { pemakaian } \\
\text { mesin agar } \\
\text { mesin tidak } \\
\text { cepat aus. }\end{array}$ \\
\hline
\end{tabular}

\section{KESIMPULAN}

Berdasarkan pembahasan yang telah dilakukan, maka dapat diambil kesimpulan bahwa kendala-kendala yang terjadi pada mesin wrapping yaitu: pisau pemotong tumpul, heater, thermo control, dan bearing rusak. Dari semua kendala-kendala yang terjadi pada mesin wrapping yang memiliki pengaruh terbesar pada kinerja mesin wrapping adalah pisau pemotong yang sudah tumpul merupakan kerusakan yang sudah sering terjadi sehingga menyebabkan plastik wrapping tersebut tidak terpotong secara rapi dan membuat buruk kualitas dari kemasan dus teh.

\section{DAFTAR PUSTAKA}

[1] Assauri, S. Manajemen Produksi dan Operasi. Jakarta: Fakultas Ekonomi Universitas Indonesia, 2008.
[2] Reza, Dicky., Supriyadi,. R. Gina. 2017. "Analisis Kerusakan Mesin Mandrel Tension Reel Dengan Menggunakan Metode Failure Mode and Effect Analysis (FMEA)". dalam Prosiding Seminar Nasional Riset Terapan, 2017, pp 190-195.

[3] Sari, D.P., Z. F. Rosyada., N. Rahmadhani. "Analisa Penyebab Kegagalan Produk Woven Bag dengan Menggunakan Metode Failure Mode and Effects Analysis (Studi Kasus di PT Indomaju Textindo Kudus)". dalam Prosiding Seminar Nasional Sains dan Teknologi, 2011, pp 6-11.

[4] Puspitasari, N. B., A. Martanto. "Penggunaan FMEA dalam Mengidentifikasi Resiko Kegagalan Proses Produksi Sarung ATM (Alat Tenun Mesin) (Studi Kasus PT. Asaputex Jaya Tegal)”. J@TI Undip: Jurnal Teknik Industri, Volume 9, Mei 2014, Pages 93-98.

[5] Hanif, R. Y., H. S. Rukmi., S. Susanty. "Perbaikan Kualitas Produk Keraton Luxury di PT. X dengan Menggunakan Metode Failure Mode and Effect Analysis (FMEA) dan Fault Tree Analysis (FTA)". Reka Integra, Volume 3, 2015, Pages 137-147.

[6] M. B. Anthony. "ANALISIS PENYEBAB KERUSAKAN HOT ROOLER TABLE DENGAN MENGGUNAKAN METODE FAILURE MODE AND EFFECT ANALYSIS(FMEA)". J. INTECH. Vol. 4, No. 1, pp. 1-8, 2016.

[7] S. Andiyanto., A. Sutrisno., C. Punuhsingon. "PENERAPAN METODE FMEA (FAILURE MODE AND EFFECT ANALYSIS) UNTUK KUANTIFIKASI DAN PENCEGAHAN RESIKO AKIBAT TERJADINYA LEAN WASTE". $J$. Poros Teknik Mesin UNSRAT. Vol. 6, No. 1, pp. 4557, 2017.

[8] R. Y. Hanif., H. S. Rukmi., S. Susanty. "PERBAIKAN KUALITAS PRODUK KERATON LUXURY DI PT. X DENGAN MENGGUNAKAN METODE FAILURE MODE and EFFECT ANALYSIS (FMEA) dan FAULT TREE ANALYSIS (FTA)". Reka Integra: Jurnal Teknik Industri (E-Journal). Vol. 3, No. 3, pp. 137147, 2015.

[9] Sukmadinata, N. S. Metode Penelitian Pendidikan. Bandung: Remaja Rosadakarya, 2011.

[10] McDermott et al. The Basics of FMEA 2nd edition. New York: CRC Press, 2009. 